\title{
Coir and Sisal Fibers as Fillers in the Production of Eucalyptus Medium Density Particleboards - MDP
}

\author{
Ricardo Gabriel de Almeida Mesquita ${ }^{a, b *}$, José Manoel Marconcinic, Anand Ramesh Sanadi ${ }^{b}$, \\ Antônia Amanda da Silva Césara, Gustavo Henrique Denzin Tonolia, Thomas Mark Venås,
}

\author{
Lourival Marin Mendes ${ }^{a}$
}

\author{
a Department of Forestry Sciences, Federal University of Lavras - UFLA, Câmpus Universitário, Caixa \\ postal 3037, CEP 37200-000, Lavras, MG, Brazil \\ ${ }^{b}$ Department of Geosciences and Natural Resource Management, Faculty of Science, University of \\ Copenhagen, Rolighedvej, 23, DK-1958, Frederiksherg, Copenhagen, Denmark \\ ${ }^{c}$ Laboratório Nacional de Nanotecnologia Aplicada ao Agronegócio - LNNA, Brazilian Agricultural \\ Research Corporation - EMBRAPA Instrumentação, Rua XV de Novembro, 1452, Caixa postal 741, \\ CEP 13560-970, São Carlos, SP, Brazil \\ ${ }^{d}$ Danish Technological Institute, Gregersensvej 1, 2630, Taastrup, Denmark
}

\author{
Received: May 9, 2016; Revised: August 18, 2016; Accepted: October 2, 2016
}

\begin{abstract}
The aim of this study was to evaluate the potential use of sisal and coir fibers in combination with Eucalyptus particles for the production of particleboard. The particleboards were produced in three layers. The first and third layers (face) were made with small Eucalyptus particles. The second layer (core) was made with big Eucalyptus particles in combination with coir or sisal fibers. The particleboards were prepared with the substitution on Eucalyptus wood for sisal and coir fibers in the particleboards core, in doses of 0,10 , and $20 \%$, relative to the total mass of particles. The particleboards were characterized by mechanical, physical and thermal properties. The results were not satisfactory for particleboards with sisal. However, for coir particleboards the physical-mechanical properties were very similar to those particleboards produced only with Eucalyptus. This work demonstrates the potential use of the coir that is commonly disposed in landfills on the Brazilian beaches.
\end{abstract}

Keywords: Coconut, lignocellulosic fiber, chipboards, thermal properties, panels

\section{Introduction}

Wood boards (or wood panels) can be defined as compounds of elements of the breakdown products of wood, such as plates, laths, particles and fibers, which are then surface coated with an adhesive to produce the boards. These new products are also known as reconstituted wood products and their properties are different from the original wood material ${ }^{1-3}$.

There are different kinds of wood boards/particleboards, among them the Medium density particleboard (MDP) and chipboards. The chipboards are composed of wood particles called slivers and form a single layer ${ }^{1-3}$. The MDPs are an evolution of the chipboards, by having three layers, two layers with smaller particles in the faces and one layer with bigger particles in the core of the board. They are usually produced with wood particles, and they are mainly used in the furniture industry. The raw material is typically used in Brazil is wood from planted forests of Pinus and Eucalyptus ${ }^{4}$. However, any lignocellulosic material can be used for the manufacture of particleboards, since they have adequate

* e-mail: ricardogam@gmail.com quality $^{5-11}$. It is also possible to mix different types of wood to other materials when the lignocellulosic materials do not show adequate quality by themselves, such as: vine pruning residues $^{12}$; poppy husk ${ }^{13}$; coir $^{5}$; coffee stem $^{14}$; maize cob $^{15}$; coffee husk ${ }^{16}$; rice hulls ${ }^{17}$ and sugarcane bagasse ${ }^{11}$. The use of natural fibers as reinforcement has aroused great interest in developing countries because of their low cost, availability, energy saving, renewable source, non-toxic and also with regard to environmental issues ${ }^{18-20}$.

Among the materials that have potential are sisal fibers which are extracted from the leaves of the plant, Agave sisalana Perr. Sisal has interesting characteristics for reinforcement, both in composites and boards due to their good mechanical properties, low density and high availability ${ }^{21,22}$. Brazil is the largest producer of sisal fibers in the world $120,000 \mathrm{t}$ per year with yields of around $800-1200 \mathrm{~kg} / \mathrm{ha}$, and accounts for $58 \%$ of the world production. In the industry, sisal is transformed into several varieties of yarns, cords, mats and blankets, being used for making various products, such as in reinforcing plastic composites, where researchers have shown promising results ${ }^{21,23-25}$. Another material with potential uses are the fibers from the husk of coconuts and these fibers are commonly know as coir, which after processing, produces 
long and short fibers. The Brazil wastes most of its coconuts husks that coir fibers while countries like India and Sri Lanka are selling their fibers for multiple uses and generate money for the local economy. It is estimated that the waste amounts to more than US\$ 60 million per year in Brazil ${ }^{21}$.

New uses of these materials can result in social, economic and environmental development for the country. Sisal cultivation is concentrated in the semiarid region of northeastern Brazil, which has few economic alternatives. Small farmers produce most of the sisal with a predominance of family agriculture. New uses for coir can transform a waste into useful products ${ }^{21}$. The objective of this study was to evaluate the potential of using sisal and coconut fibers in combination with Eucalyptus particles for the production of MDP.

\section{Material and Methods}

\subsection{Raw material}

Eucalyptus urophylla particles, sisal fibers (supplied by Embrapa Cotton) and coconut fibers (coir) were used along with urea formaldehyde (UF) as adhesive. The Eucalyptus urophylla wood was 7 years old with a basic density of 0.560 g.cm ${ }^{-3}$ and bulk density of 0.586 g.cm ${ }^{-3}$ (11.8\% moisture). This wood has grown in Paracatu-MG-Brazil and obtained from Companhia Mineira de Metais.

The sliver particles were generated with a hammer mill and subsequently classified in sieves of 14, 40 and 120 mesh. The particles retained in the sieves of 120 and 40 mesh were used for the faces and core, respectively.

Asasutjarit et al. ${ }^{26}$ found that the best performance of cement/coir boards were those with coir fiber lengths between 1 to $6 \mathrm{~cm}$. According to those researchers long fibers decrease the workability and increase the void space. Besides this, the longer the fiber length both water absorption and thickness swelling was higher. Based on this the lignocellulosic fibers were cut manually with the aid of scissors to approximately $3 \mathrm{~cm}$ lengths.

The particles and fibers were dried in an oven at $90^{\circ} \mathrm{C}$ until final moisture content of $4 \%$.

The adhesive (UF) used had the following characteristics$\mathrm{pH}=9.15$, solids content $=53 \%$ and viscosity $=0.261$ Pa.s.

\subsection{MDP production}

The adhesive (UF) was spread using a rotary blender in two stages. First the adhesive was applied to smaller particles in a proportion of $11 \%$ (dry basis weight of the particles). The bigger particles (plus fibers) were coated with the adhesive in a proportion of $8 \%$ (dry basis weight of the particles). More adhesive was used for the smaller particles because they have higher surface area to volume coated to larger particles and therefore need more adhesive to guarantee good adhesion. Three particleboards were produced for each treatment with a nominal density of $0.750 \mathrm{~g} . \mathrm{cm}^{-3}$ in three layers, face/core/face, with the proportion of 20/60/20 (basis of particles weight), respectively. Three sisal/coir proportion were used $(0,10$ and $20 \%)$ and were mixed with the Eucalyptus particles in the core (Table 1). As mentioned earlier the only smaller wood particles of 120 mesh were used as surface layers, with no coir or sisal present.

Table 1: Treatments with their composition.

\begin{tabular}{lcc}
\hline Treatments & $\begin{array}{c}\text { Face } \\
(20 \% \text { each })\end{array}$ & Core $(60 \%)$ \\
\hline EU & E. urophylla & $100 \%$ E. urophylla \\
CO-10 & E. urophylla & $90 \%$ E. urophylla $+10 \%$ of coir \\
CO-20 & E. urophylla & $80 \%$ E. urophylla $+20 \%$ of coir \\
SI-10 & E. urophylla & $90 \%$ E. urophylla $+10 \%$ of sisal \\
SI20 & E. urophylla & $80 \%$ E. urophylla $+20 \%$ of sisal \\
\hline
\end{tabular}

The particle mattress was subjected to a pre-pressing in a hydraulic press at a pressure of $0.78 \mathrm{MPa}$ and subsequently transferred to a hot press. The hot press cycle underwent a pressure of $3.92 \mathrm{MPa}$ at $160^{\circ} \mathrm{C}$ for 8 minutes. After the pressing and subsequent cooling the edges of the four sides of the boards were cut off, resulting in final dimensions of $47 \times 47 \times 1.5 \mathrm{~cm}$. The boards were then placed in a controlled chamber for $\left(22 \pm 2^{\circ} \mathrm{C}\right.$ and $65 \pm 5 \%$ of moisture $)$ for acclimatization until constant weight was achieved prior to physical and mechanical characterization. The production steps are summarized below (Figure 1).
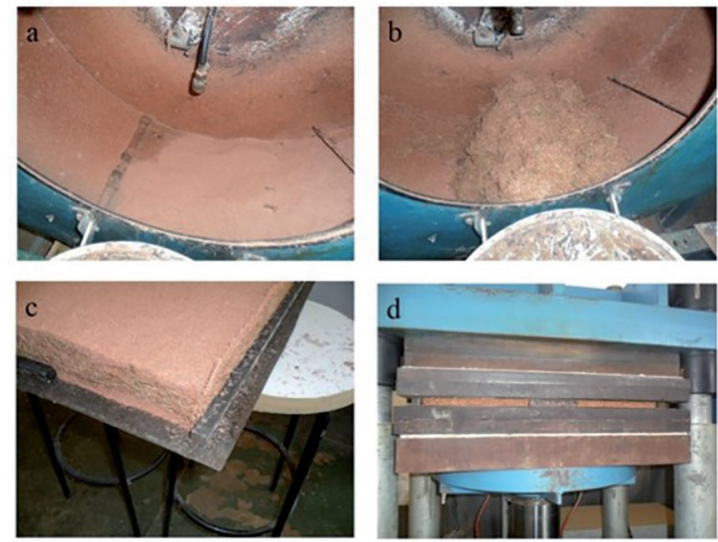

Figure 1: MDP production. (a) Adhesive application to smaller particles. (b) Adhesive application to bigger particles plus fibers. (c) Particle mattress after the pre-pressing. (d) Particle mattress during the hot press.

\subsection{Physical, mechanical and thermal properties evaluated}

The particleboards were characterized by testing their physical, thermal and mechanical tests using standardized tests specified in Table 2. 
Table 2: Properties evaluated

\begin{tabular}{lll}
\hline Properties & Symbol & $\begin{array}{l}\text { Standard/ } \\
\text { Equipment }\end{array}$ \\
\hline Density & D & EN 323 27 \\
Compression ratio & CR & MALONEY 28 \\
Water absorption after 2h & WA2h & ASTM D1037 29 \\
Water absorption after 24h & WA24h & ASTM D1037 29 \\
Thickness swelling after 2h & TS2h & ASTM D1037 29 \\
Thickness swelling after 24h & TS24h & ASTM D 1037 29 \\
Thickness non-return ratio & TNRR & ASTM D1037 29 \\
Bending modulus & MOE & DIN 52362 30 \\
Bending strength & MOR & DIN 52362 ${ }^{30}$ \\
Internal bond & IB & ASTM D1037 29 \\
Thermal conductivity & TC & ISOMET \\
\hline
\end{tabular}

The compression ratio was calculated by dividing the density of the particleboard by the density of the material. The dimensions of the particleboards and wood, for the calculation of the volume, were measured with a caliper, but the sisal and coconut dimensions have been calculated using a microscope.

The thermal properties were measured with the equipment ISOMET model 2104. The samples with $6 \times 6 \times 1.5 \mathrm{~cm}$ were stored in a controlled chamber $\left(20^{\circ} \mathrm{C}\right.$ and $65 \%$ of moisture $)$ until constant weight before being tested. Five samples were measured for each set of samples.

The data were analyzed as a completely randomized design and the properties were compared by the mean values and standard deviation.

\section{Results and Discussion}

\subsection{Density, moisture and compression ratio}

The density and moisture of the boards are graders characteristics that ensure fairness between treatments, thus allowing to proceed with the comparison between the average values of physical and mechanical properties. The density of the MDPs ranged from 0.757 to $0.776{\mathrm{~g} . \mathrm{cm}^{-3}}^{-}$(Table 3). All the boards were classified as medium density, referring to boards with density between 0.590 to $0.800 \mathrm{~g} \cdot \mathrm{cm}^{-3}{ }^{1}$. The moisture ranged from 9.43 to $9.80 \%$. Both those properties showed a slight variation of the mean values.
The CR is the relation between the density of the boards by the density of the material. As noted in Table 3, the CR values increased as it included sisal/coir fibers and this is due to the lower density. The densities of the material were measured to be; sisal 0.368 g.cm ${ }^{-3}(12.75 \%$ of moisture); coir $0.460{\mathrm{~g} . \mathrm{cm}^{-3}}^{-3}\left(12.15 \%\right.$ of moisture); Eucalyptus $0.586 \mathrm{~g} . \mathrm{cm}^{-3}$ (11.8\% of moisture). According to Maloney ${ }^{28}$ the ideal CR values are between 1.3 and 1.6. The recommendation of the author to the mentioned CR range is partly because of CR lower than 1.3 result in lower mechanical strength and high values of CR more than 1.6 creates problems as dimensional instability of the boards. All the MDPs in this study had a $\mathrm{CR}$ in the recommended range between 1.3 to 1.6 .

\subsection{Bending (MOE and MOR)}

The mean values of MOE and MOR for the different treatments are shown in Figures 2 and 3, respectively. There was very little difference in the MOE between the samples CO-20, EU and CO-10. This was also true for MOR for EU, CO-10 and CO-20. The coir particleboards values are below those found for Khedari et al. ${ }^{31}$ however, the authors produced particleboards only with coir, which resulted in an MOR of $25 \mathrm{MPa}$ and MOE of $2857 \mathrm{MPa}$. This probably because using a single material of only coir fibers would probably have better dispersion than in the present case where fibers are mixed with particles. Secondly, longer fibers can result in improved reinforcement instead of a mix or particle and fibers.

The MDPs with higher amount of sisal and coir (20\%) showed higher standard deviation than the MDPs with $10 \%$ of sisal and coir. This may be due to factors related to the processing, since the distribution of the particles and fibers were performed manually, making it more difficult to evenly disperse the two materials when the amount of fibers is increased. During the adhesive application, it was observed that sisal fibers tend to clump together in the rotary blender and it is thus difficult for the UF to get in between the fiber clumps and this is reflecting by lower MOE and MOR of the boards.

Coconut coir has low amounts of hemicellulose and a high amount of lignin $41-45 \%{ }^{32-34}$. Lignin has the ability to act as an adhesive and increases the strength of the fiber bond but this depends on the type of lignin and amount of moisture and temperature of processing ${ }^{35-37}$. Particleboards

Table 3: Values of the particleboards density, humidity and compression ratio.

\begin{tabular}{|c|c|c|c|}
\hline Treatments & Density $\left(\mathrm{g} . \mathrm{cm}^{-3}\right)$ & Moisture (\%) & Compression ratio \\
\hline $\mathrm{EU}$ & $0.757 \pm 0.007$ & $9.74 \pm 0.07$ & $1.3 \pm 0.0$ \\
\hline $\mathrm{CO}-10$ & $0.760 \pm 0.026$ & $9.63 \pm 0.19$ & $1.4 \pm 0.1$ \\
\hline $\mathrm{CO}-20$ & $0.773 \pm 0.010$ & $9.80 \pm 0.07$ & $1.4 \pm 0.0$ \\
\hline SI-10 & $0.776 \pm 0.010$ & $9.53 \pm 0.05$ & $1.4 \pm 0.0$ \\
\hline SI-20 & $0.763 \pm 0.007$ & $9.47 \pm 0.10$ & $1.4 \pm 0.0$ \\
\hline
\end{tabular}

Mean values followed by the standard deviation. Density (Bulk density) 


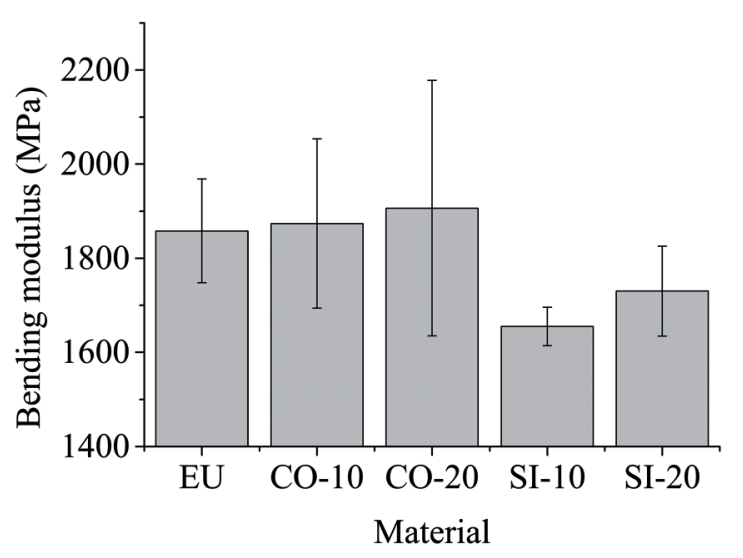

Figure 2: Histogram of the mean values for bending modulus (MOE). Bars indicate standard deviation.

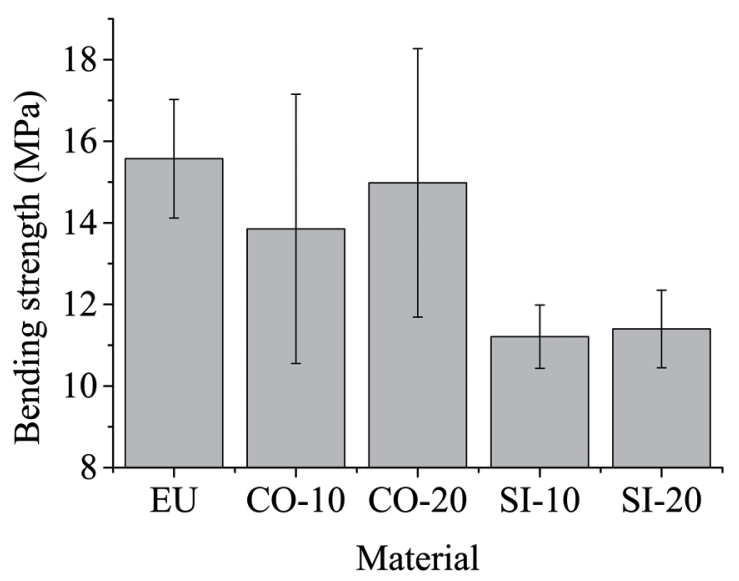

Figure 3: Histogram of the mean values for bending strength (MOR). Bars indicate standard deviation

that have a high lignin content will be stronger as long as sufficient moisture and temperature is used. High amount of coir improves the cross-links between fibers and decreases space and void ${ }^{32}$. Besides that, sisal is a hard fiber and it is more difficult to press than coir, which increase the amount of void, impairing the mechanical properties (MOR, MOE and IB).

Colli et al. ${ }^{5}$ produced particleboard from Paricá wood (Schyzolobium amazonicum) with coir $(0,10,20$ and 30\%). For MOE, the coir inclusion did not changed the mean values, however the mean values for MOR were higher for boards with high amount of coir (20 and 30\%). It is possible that better dispersion of fibers resulted in the fibers reinforced the boards more efficiently and this effect is greater with higher amounts of fibers.

Melo et al. ${ }^{17}$, investigated the association of rice hulls $(0$, $20,40,60,80$ and $100 \%$ ) with wood (Eucalyptus grandis) in chipboards with $0.650 \mathrm{~g} . \mathrm{cm}^{-3}$ of nominal density. The authors observed a decrease in the mechanical property values with an increase in the percentage of rice husks- here MOE decreased from 1225 to $196 \mathrm{MPa}$ and MOR from 14.7 to 3.9 MPa. César et al. ${ }^{14}$ and Mendes et al. ${ }^{16}$ observed the same trend in with the use of coffee stem and coffee husk in chipboards. This may be due to waxy surface layers on the husks which could create a weak boundary layer ${ }^{38,39}$, although this aspect was not studied by the authors.

ANSI A208. $1^{40}$ stipulates the average minimum values of $1764 \mathrm{MPa}$ for MOE and 11.3 for MOR for particleboards/ chipboards made with urea-formaldehyde (class M1). In this study, none of the MDPs made with sisal fibers met the minimum requirements for MOE, however, for MOR all sisal MDPs attained the average minimum value required by the standard. In the case of coir/wood boards both MOE and MOR exceeded the ANSI standards noted above.

\subsection{Internal bond strength (IB)}

The mean IB values of all the boards in this study are shown in Figure 4. The data demonstrate that the IB decreased with an increase of the sisal and coir amount, although the decrease was more pronounced for sisal MDPs. The decrease in IB values can be attributed to the sizing (dispersion of the UF adhesive) process of particles and fibers, because the clumps of fibers may have impaired the adhesive dispersion process and the uniform distribution of the wood particles and fibers. This was especially visible in sisal MDPs, which after sizing, clumps of fibers were observed. As mentioned previously, these fiber clumps prevented the dispersion of the adhesive in the middle of the clumps, thereby impairing the bonding of the materials, since some regions may have had no adhesive. The application of the adhesives is directly related to the quality of gluing the boards and the IB test $t^{41,2}$. The reduction in the length of the sisal fibers in future work can facilitate and improve the mixing of particles and fibers, which in turn can improve the dispersion of the adhesive and bonding.

This decrease in IB was also observed while using particles of corncob by Scatolino et al. ${ }^{15}(0,2550,75$, $100 \%$ ) mixed with wood (Pinus oocarpa) in chipboards.

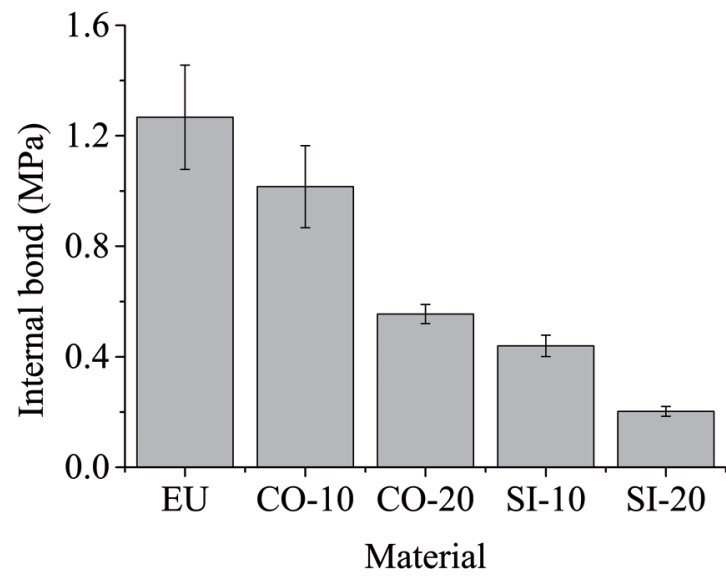

Figure 4: Histogram of the mean values for the internal bond property (IB). Bars indicate standard deviation 
The mean values decreased from 1.1 to $0.3 \mathrm{MPa}$ with the corn cob inclusion. The authors attributed the results to the low density of corncob, because the increase in the number of particles entailed a reduced availability of adhesive per particle, which reduce the adhesion strength and therefore the IB strength. Materials that have lower density generate a larger amount of particles for a given weight and thus a higher specific surface requires higher amounts of adhesive to obtain good properties ${ }^{41}$. The same decrease was observed for Mendes et al. ${ }^{16}$ with the inclusion of coffee husk in chipboards made from Eucalyptus urophylla and Mesquita et al. ${ }^{6}$ with inclusion of sisal.

The minimum IB required by ANSI A208. $1^{40}$ is $0.40 \mathrm{MPa}$ for UF adhesive (MS class). Only the MDPs with $20 \%$ of sisal incorporation did not meet the minimum requirements.

\subsection{Thickness swelling (TS) and water absorption (WA)}

The mean values for TS properties, TNRR and WA for all treatments, are presented below (Figures 5 and 6).

The MDPs reinforced with coir fibers showed satisfactory results for TS and WA after 2 and 24 hours. The mean values for CO-10 and CO-20 were very similar to those made just with particle wood (EU). However, the addition of sisal resulted in a significant decrease of these properties and this is probably due to higher amount of voids because of poor particle and fiber dispersion along with fiber clumping and poor bonding that facilitated the entry of water. MDPs with sisal showed almost the double values of TS and WA after 24 hours, compared to EU, CO-10 and CO-20. Similar results had been observed by César et al ${ }^{14}$ working with lignocellulosic waste and the authors attributed this to bonding problems caused by possible chemical incompatibility or poor distribution between the adhesive and particles. The same trends were observed for Mendes et al. ${ }^{16}$ with the inclusion of coffee husk in chipboards. Coconut coir has low amounts of hemicellulose and a high amount of lignin $41-45 \% \%^{32-34}$. Lignin has the ability to act as an adhesive and increases the strength of the fiber bond but this depends on the type of lignin and amount of moisture in the material ${ }^{35-37}$. Particleboards that have high lignin content will be rather stronger with a higher water resistance. Higher amount of coir improves the cross-links between fibers and decreases space and void 32. Sisal is a hard fiber and it is more difficult to press than coir, which increase the amount of void, increasing the WA.

Keskin et al. ${ }^{13}$ found similar results for TS after 2 and 24 hours using wood pine plus poppy husk up to $25 \%$. The treatment with $25 \%$ of poppy husk was statistically equal to those made only with wood pine. Using higher amount of poppy husk (50, 75 and 100\%) increased the TS and decreased the IB, MOE and MOR.

The UF adhesive have low water and weather resistance. The aminomethylene linkage is susceptible to hydrolysis,

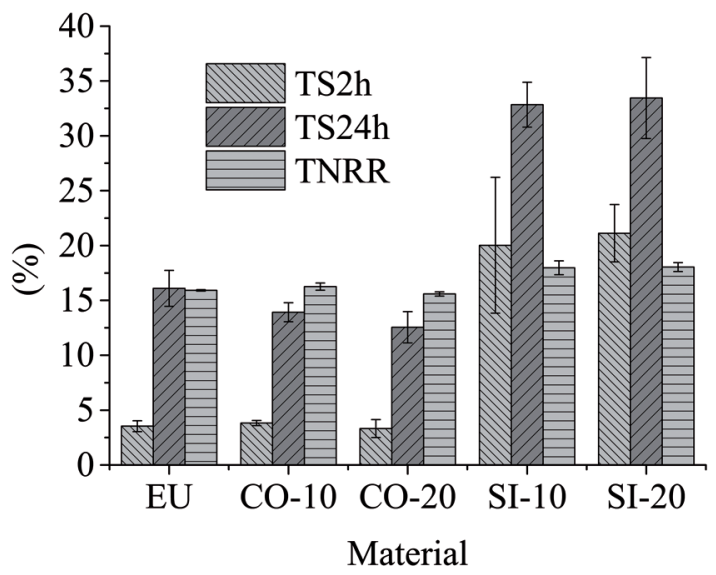

Figure 5: Histogram of the mean values for the thickness swelling after 2 hours (TS2h), thickness swelling after 24 hours (TS24h) and thickness non-return ratio (TNRR). Bars indicate standard deviation

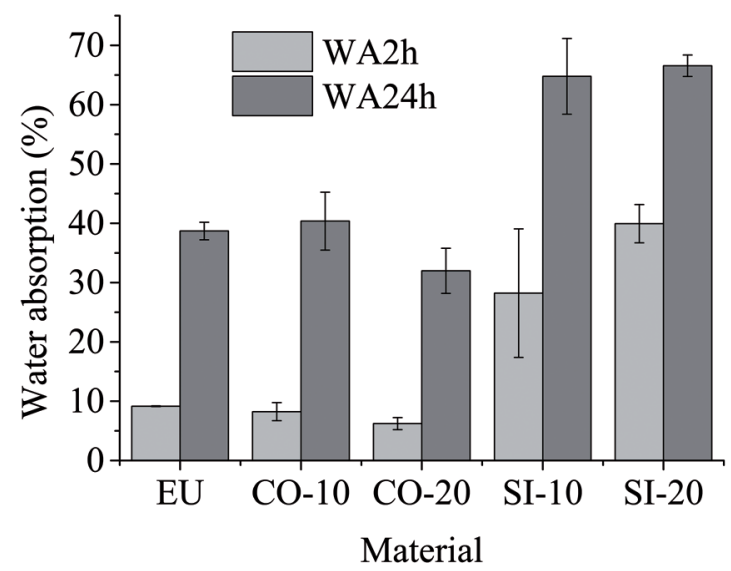

Figure 6: Histogram of the mean values for the water absorption after 2 (WA2h) and water absorption after 24 hours (WA24h). Bars indicate standard deviation

which means that the reaction that forms the UF is reversibile when it is attack by water and this is also responsible for the formaldehyde emission. The water causes swelling and therefore movement of the structural components of the MDP contributing to break the bonding between resin and wood surface sites due to mechanical forces and stresses ${ }^{42-44}$.

Colli et al. ${ }^{5}$ produced particleboard from Paricá wood (Schyzolobium amazonicum) with coir inclusion $(0,10,20$ and $30 \%$ ) and they did not find difference between the mean values for WA and TS. Khedari et al. ${ }^{31}$ produced particleboards with only coir and the boards had a $53 \%$ for TS and $78 \%$ for WA. However, those authors produced particleboards with a lower density $\left(0,648 \mathrm{~g} . \mathrm{cm}^{-3}\right)$, which contribute to increased voids thus increasing the WA and TS values.

Scatolino et al ${ }^{15}$ observed the same for WA when they increased the amount of corn cob in chipboards, but for TS24h the mean values decreased. The authors attributed this to the increase of compression ratio and the largest amount 
of extractive corn cob. Apart from WA and TS, extractives such as surface waxes can result in a weak boundary layer ${ }^{38}$ and this will play a role in MOR and IB strengths such as the work on wheat straw ${ }^{39}$, as discussed earlier.

According Hillig et al. ${ }^{45}$ and Malloney ${ }^{28}$ the physicalmechanical properties of the boards are influenced by the $\mathrm{CR}$ and low $\mathrm{CR}$ values do not produce good contact between the particles, impairing the bonding and strength of the boards. In addition the boards have higher spaces/voids which facilitate the water absorption. However in the current study the CR is within the range recommended (1.3 to 1.6) suggesting that poor adhesive dispersion for sisal fibers and/ or possible chemical incompatibility between adhesive and material due to extractives or otherwise.

The ANSI A208. $1^{40}$ provides values for only the TS24h that is $8 \%$ for the chipboards produced with urea-formaldehyde. Therefore, none of the MDPs produced met the minimum requirement stipulated by the standard.

\section{Thermal Properties}

\subsection{Thermal conductivity}

The samples for thermal properties were stored in a controlled chamber with $20^{\circ} \mathrm{C}$ and $65 \%$ of moisture until constant weight. The samples had the density and moisture measured before the test (Table 4).

The thermal conductivity was directly related to the density of the MDPs (Table 4 and Figure 7) and the conductivity decreases with density. This can be explained by the change in the number and/or volume of voids both between and inside particles owing to their densification. These voids are occupied by air, and since air has a lower thermal conductivity than the wood ${ }^{46}$. The relationships between density and thermal conductivity were also observed by for Bekhta and Dobrowolska ${ }^{46}$ when studying the properties of wood-gypsum boards and also by Sampathrajan et al. ${ }^{47}$ measuring properties of boards made from farm residues.

Some researchers try to produce materials with low thermal conductivity, so as to reduce heat transfer and decrease the energy consumption of the building facilities. Thermal conductivity is an indicator of the value of a material as a heat insulator and lower thermal conductivity indicates that the material is better for thermal insulation. This is interesting for energy saving when used for ceiling and wall insulating material/boards ${ }^{32,48}$. These same authors found values for particles boards $\left(0.258 \mathrm{~g} . \mathrm{cm}^{-3}\right)$ about $0.029 \mathrm{~W} \mathrm{~m}^{-1} \mathrm{~K}^{-1}$, and they recommended those boards for thermal insulation.

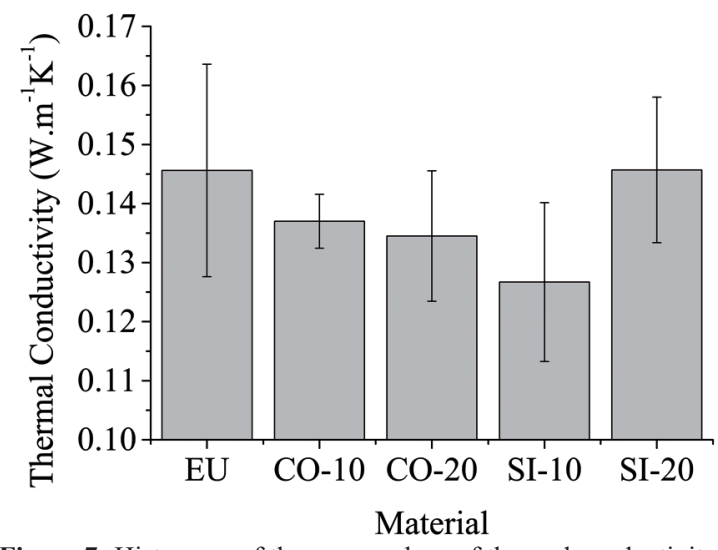

Figure 7: Histogram of the mean values of thermal conductivity. Bars indicate standard deviation

Khedari et al. ${ }^{31}$ produced coir particleboards just with coir and found mean values of $0.1445 \mathrm{Wm}^{-1} \mathrm{~K}^{-1}\left(0.648 \mathrm{~g} . \mathrm{cm}^{-3}\right.$ of board density). Lower values $\left(0.1117 \mathrm{Wm}^{-1} \mathrm{k}^{-1}\right)$ were found for particleboards $\left(0.611 \mathrm{~g} . \mathrm{cm}^{-3}\right)$ made with $90 \%$ of coir and $10 \%$ of durian ${ }^{32}$.

Yapici et al. ${ }^{49}$ founded that the thermal conductivity were affected by adhesive ratio and pressing time for oriented strand boards (OSB). It was observed that increasing the amount of adhesive and pressing time increases the thermal conductivity. The thermal conductivity values, found by Yapici et al. ${ }^{49}$, range from 0.129 to $0.170 \mathrm{Wm}^{-1} \mathrm{k}^{-1}$. This is obvious since higher the amount of adhesive and higher pressure reduces voids and increases conductivity.

\section{Conclusions}

In general, the inclusion of sisal fibers in the MDP production was unfeasible, since it resulted deterioration in all properties analyzed. The inclusion of coconut fibers proved feasible, since for most of the properties the MDPs with coconut achieved the same performance of MDPs from Eucalyptus urophylla. The use of this material contributes to the development of more sustainable materials, since it is a waste, which often is rather simply discarded on beaches.

Further studies need to be done in order to study ways to improve the homogenization of the material and the adhesive application. It should also verify the economic viability of the use of this waste, once the technical feasibility has already been demonstrated in this work.

\section{Acknowledgement}

The authors are grateful for the support of Coordenação de Aperfeiçoamento de pessoal de Nível Superior (CAPES),

Table 4: Apparent density and moisture of the samples used for the thermal properties

\begin{tabular}{lccccc}
\hline & EU & CO-10 & CO-20 & EU-10 & EU-20 \\
\hline Density $\left(\right.$ g.cm $\left.{ }^{-3}\right)$ & $0.774 \pm 0.081$ & $0.727 \pm 0.026$ & $0.713 \pm 0.053$ & $0.702 \pm 0.068$ \\
Moisture (\%) & $9.37 \pm 0.09$ & $9.28 \pm 0.08$ & $9.33 \pm 0.13$ & $9.29 \pm 0.07$ & $9.09 \pm 0.05$ \\
\hline
\end{tabular}


Fundação de Amparo à Pesquisa do Estado de Minas Gerais (Fapemig), Conselho Nacional de Desenvolvimento Científico e Tecnológico (CNPq), RELIGAR, Embrapa Instrumentação and Embrapa Algodão, Federal University of Lavras (UFLA), University of Copenhagen and Danish Technological Institute.

\section{References}

1. Iwakiri S. Painéis de madeira reconstituída. Curitiba: Fupef; 2005.247p

2. Kelly MW. Critical literature review of relationships between processing parameters and physical properties of particleboard. General technical report, FPL-10; 1977. Available from: <http:// www.fpl.fs.fed.us/documnts/fplgtr/fplgtr10.pdf $>$. Access in: 23/06/2015

3. Maloney TM. The family of wood composite materials. Forest Products Journal. 1996;46(2):19-26.

4. Barros Filho RM. Painéis aglomerados a base de bagaço de cana-de-açúcar e resinas uréia formaldeído e melanina formaldeído. [Dissertation]. Ouro Preto: Federal University of Ouro Preto; 2009. 99 p.

5. Colli A, Vital BR, Carneiro ACO, Silva JC, Carvalho AMML, Della Lucia RM. Propriedades de chapas fabricadas com partículas de madeira de paricá (Schyzolobium amazonicum Huber ex. Ducke) e fibras de coco (Cocos nucifera L.). Revista Árvore. 2010;34(2):333-338.

6. Mesquita RGA, Mendes LM, Mendes RF, Tonoli GHD, Marconcini JM. Inclusion of sisal bundles in the production of eucalyptus MDP panels. Scientia Forestalis. 2015;43(105):75-82.

7. Soratto DN, Cunha AB, Vital BR, Carneiro ACO, Costa FR. Effects of the addition of splinter shell in quality of MDP panels produced with Eucalyptus sp. Ciência da Madeira. 2013;4(1):46-59.

8. Trianoski R, Iwakiri S, Matos JLM, Chies D. Use of Cryptomaria japônica wood for the production of particleboard. Scientia Forestalis. 2013;41(97):57-64.

9. Oliveira SL, Mendes RF, Mendes LM, Freire TP. Particleboard panels made from sugarcane bagasse: characterization for use in the furniture industry. Materials Research. 2016;19(4):914-922.

10. Guimarães BMR, Bufalino L, Guimarães Júnior JB, Mendes RF, Mendes LM, et al. $\mathrm{NaOH}$ treatment impact in the dimensional stability of banana pseudostem particleboard panels. Key Engineering Materials. 2014;600:447-451.

11. Barros Filho RM, Mendes LM, Novack KM, Aprelini LO, Botaro VR. Hybrid chipboard panels based on sugarcane bagasse, urea formaldehyde and melamine formaldehyde resin. Industrial Crops and Products. 2011;33(2):369-373.

12. Özen E, Göktas O, Kasal A, Efe H, Demirci S. Bending moment capacity of L-type furniture corner joints constructed of particleboard produced from vine pruning residues. Wood Research. 2014;59(2):313-322.

13. Keskin H, Kucuktuvek M, Guru M. The potential of poppy (Papaver somniferum Linnaeus) husk for manufacturing woodbased particleboards. Construction and Building Materials. 2015;95:224-231.
14. César AAS, Bufalino L, Macedo LB, Mesquita RGA, Protásio TP, Mendes LM. Use of Coffee Plant Stem in the Production of Conventional Particleboards. Key Engineering Materials. 2014;600:703-708.

15. Scatolino MV, Silva DW, Mendes RF, Mendes LM. Use of maize cob for production of particleboard. Ciência e Agrotecnologia. 2013;37(4):330-337.

16. Mendes RF, Mendes LM, Guimarães Junior JB, Mori FA, César AAS. Effect of the incorporation of coffee husks on the physicalmechanical properties of Eucalyptus urophylla S.T. Blake particleboards. Ciência e Agrotecnologia. 2010;34(3):610-617.

17. Melo RR, Santini EJ, Haselein CR, Stangerlin DM. Propriedades físico-mecânicas de painéis aglomerados produzidos com diferentes proporções de madeira e casca de arroz. Ciência Florestal. 2009;19(4):449-460.

18. Yang HS, Kim DJ, Kim HJ. Rice straw-wood article composite for sound absorbing wooden construction materials. Bioresource Technology. 2003;86(2):117-121.

19. MacVicar R, Matuana LM, Balatinecz JJ. Aging mechanism in cellulose fiber reinforced cement composites. Cement Concrete Compomposites. 1999;21(3):189-96.

20. Soykeabkaew N, Sian C, Gea S, Nishino T, Peijs T. All-cellulose nanocomposites by surface selective dissolution of bacterial cellulose. Cellulose. 2009;16(3):435-444.

21. Brazilian Fibres; 2013. Available from: $<$ http://www.brazilianfibres. com. br/?page_id=17\&lang=pt>. Access in: 12/03/2013.

22. Martin AR, Martins MA, Mattoso LHC, Silva ORRF. Chemical and structural characterization of sisal fibers from Agave sisalana variety. Polimeros. 2009;19(1):40-46.

23. Carvalho LH, Cavalcanti WS. Properties of polyester/hybrid sisalglass fabrics. Polimeros. 2006;16(1):33-37.

24. Joseph K, Medeiros ES, Carvalho LH. Tensile properties of unsaturated polyester composites reinforced by short sisal fibers. Polimeros. 1999;9(4):136-141.

25. Singh B, Gupta M, Verma A. Influence of fiber surface treatment on the properties of sisal-polyester composites. Polymer Composites. 1996;17(6):910-918

26. Asasutjarit C, Hirunlabh J, Khedari J, Charoenvai S, Zeghmati B, Cheul Shin U. Development of coconut coir-based lightweight cement board. Construction Building Materials. 2007;21(2):277-288

27. APA Europe. Individual Standards. EN 323. Wood based panels -Determination of density. Brussels: APA Europe: 1993.

28. Maloney TM. Modern particleboard and dry-process fiberboard manufacturing. San Francisco: Miller Freeman, São Francisco; 1993.

29. ASTM International. ASTM D1037-12. Standard methods of evaluating properties of wood-base fiber and particles materials. West Conshohocken: ASTM International; 2006.

30. DIN - Normen Für Holzfaserplaten Spanplatten Sperrholz. DIN 52362. Testing of wood chipboards; bending test, determination of bending strength. Berlin: DIN; 1982.

31. Khedari J, Charoenvai S, Hirunlabh J. New insulating particleboards from durian peel and coconut coir. Buildingand Environment. 2003;38(3):435-441. 
32. Khedari J, Nankongnab N, Hirunlabh J, Teekasap S. New lowcost insulation particleboards from mixture of durian peel and coconut coir. Building Environment. 2004;39(1):59-65.

33. Mizanur Rahman M, Khan MA. Surface treatment of coir (Cocos nucifera) fibers and its influence on the fibers' physicomechanical properties. Composites Science Technology. 2007;67(11-12):2369-2376.

34. Rout J, Misra M, Tripathy SS, Nayak SK, Mohanty AK. The influence of fibre treatment on the performance of coir-polyester composites. Composites Science Technology. 2001;61(9):1303-1310.

35. Olsson AM, Salmen L. Viscoelasticity of in situ lignin as affected by structure: sowftwood vs. hardwood. In: Glasser W, ed. Viscoelasticity of biomaterials. Washington: American Chemical Society; 1992. p. 133-143.

36. Stelte W, Holm JK, Sanadi AR, Barsberg S, Ahrenfeldt J, Henriksen UB. A study of bonding and failure mechanisms in fuel pellets from different biomass resources. Biomass and Bioenergy. 2011;35(2):910-918.

37. Stelte W, Clemons C, Holm JK, Ahrenfeldt J, Henriksen UB, Sanadi AR. Thermal transition of the amorphous polymers in wheat straw. Industrial Crops and Products. 2011;34(1):1053-1056.

38. Bikerman JJ. Causes of poor adhesion: weak boundary layers. Industrial \& Engineering Chemistry. 1967;59(9):40-44.

39. Stelte W, Clemons C, Holm JK, Ahrenfeldt J, Henriksen UB, Sanadi AR. Fuel pellets from wheat straw: The effect of lignin glass transition and surface waxes on pelletizing properties. Bioenergy Research. 2012;5(2):450-458.
40. American National Standard (ANS). Mat-formed wood particleboard: Specification ANSI/A 208.1. Gaithersburg: National Particleboards Association; 1993.

41. César AAS, Mendes LM, Bufalino L, Protásio TP, Guimarães Junior JB, Mori FA, et al. Analysis of the gluing quality pf particles from OSB panels in laboratorial conditions. Cerne. 2014;20(4):501-508.

42. Dunky M. Urea-formaldehyde (UF) adhesive resins for wood. International Journal of Adhesion and Adhesives. 1998;18(2):95-107.

43. Dunky M. Adhesives based on formaldehyde condensation resins. Macromolecular Symposia. 2004;217(1):417-430.

44. Liu YQ, Tian Y, Zhao GZ, Sun YY, Zhu FT, Cao Y. Synthesis of urea-formaldehyde resin by melt condensation polymerization. Journal of Polymer Research. 2008;15:501-505.

45. Hillig E, Haselein CR, Santini EJ. Mechanical properties of flakeboards made from pine, eucalyptus and wattle wood. Ciência Florestal. 2002;12(1):59-70.

46. Bekhta P, Dobrowolska E. Thermal properties of wood-gypsum boards. Holz als Roh- und Werksofft. 2006;64(5):427-428.

47. Sampathrajan A, Vijayaraghavan NC, Swaminathan KR. Mechanical and thermal properties of particle boards made from farm residues. Bioresource Technology. 1992;40(3):249-251.

48. Tangjuank S, Kumfu S. Particle boards from Papyrus fibers as thermal insulation. Journal of Applied Science. 2011;11(14):2640-2645.

49. Yapici F, Gündüz G, Özçifçi A. The effects of some production factors on thermal conductivity of oriented strand board. Technology. 2010;13(2):65-70. 